1. MBBS,

Senior Lecturer,

Department of Physiology JMDC 22-23 Shaheed-i-Millat Rd, Karachi

2. MBBS, MSc, ADHPE

Faculty, Department of Community Medicine

JMDC 22-23 Shaheed-i-Millat Rd, Karachi

3. MBBS Student,

Ziauddin Medical University

4. MBBS Student,

Ziauddin Medical University

Correspondence Address:

Dr. Ghazala Masood Farrukh, MBBS

Senior Lecturer Physiology

JMDC 22-23 Shaheed-i-Millat Rd

Karachi

ghazala31@gmail.com

Article received on:

02/07/2016

Accepted for publication:

25/08/2016

Received after proof reading:

10/09/2016

\title{
IRON DEFICIENCY ANEMIA;
}

DIETARY PATTERN OF IRON INTAKE FROM INDIGENOUS IRON RICH FOOD IN FEMALE IDA PATIENTS AND CORRESPONDING HEMATOLOGICAL PROFILES: A CROSS SECTIONAL STUDY AT A TERTIARY CARE HOSPITAL IN KARACHI ghazala31@gmail.com

\section{Dr. Ghazala Masood Farrukh', Dr. Zainab Hasan², Samar Ikram³, Batha Tariq ${ }^{4}$}

\begin{abstract}
Globally about two billion people suffer from anemia of various types amongst which Iron Deficiency Anemia (IDA) is the most prevalent type. According to National Nutrition Survey of Pakistan 2011 (NNS), $50.4 \%$ of non-pregnant females suffer from IDA, despite the fact that a variety of low cost, indigenous food sources of iron are available, affordable and accessible in Pakistan. IDA is a risk factor for complications of pregnancy and low birth weight baby and is also an independent cause of morbidity and mortality in all ages. Therefore this study was conducted to determine the dietary patterns of iron intake in females of reproductive age group who had IDA without any other known cause. Study Design: A cross sectional study. Setting: Three tertiary care centers of Ziauddin Hospital located at Clifton, Kemari and North Nazimabad. Methods: Reproductive age females suffering from IDA according to their CBC profile within three months prior to the study were selected through purposive sampling. Females taking iron supplements or with any known cause of iron deficiency were excluded. Total of 141 eligible and consenting IDA patients filled a 7 Day dietary recall questionnaire to determine the iron intake of indigenously available iron rich foods and blood sample was collected for hematological profiles and iron studies. Results: Mean iron intake was $6.41 \pm$ $4.39 \mathrm{mg} /$ day. Median heme and non heme iron intake was $8.0 \mathrm{mg}$ and $28.0 \mathrm{mg}$ per week, respectively. $52.4 \%$ of our study population had moderate IDA, $38.2 \%$ had pica for one or more substance and almost all suffered from one or more symptoms of iron deficiency. Majority of the population was consuming non-heme sources of iron. Conclusion: The iron consumption from indigenous dietary sources is very low and contributes significantly to development of IDA. Increasing awareness regarding signs and symptoms of IDA and common dietary sources of iron will contribute to screening, early diagnosis and correction of the iron deficit thus promoting health and preventing complications.
\end{abstract}

Key word: Iron Deficiency Anemia, dietary iron content, iron rich indigenous food, signs and symptoms of anemia.

Article Citation: Farrukh GM, Hasan Z, Ikram S, Tariq B. Iron Deficiency Anemia; Dietary pattern of iron intake from indigenous iron rich food in female IDA patients and corresponding hematological profiles: a cross sectional study at a tertiary care hospital in Karachi. Professional Med J 2016;23(9):1092-1098. DOI: $10.17957 / T P M J / 16.3520$

\section{Statement of novelty}

The topic of this article, Iron Deficiency Anemia and dietary habits in such patients is pertinent to our region, as being a developing economy; with accompanied health budget issues, this article will help in raising further, awareness among doctors of today that anemia, though a nuisance of a disease is very much prevalent in all strata of our society especially females of child bearing age. This article presents the actual scenario of IDA patient's dietary iron content, that they are consuming less iron and whatever they are consuming is from non heme iron group of foods which is reabsorbed less rapidly by enterocytes. Furthermore the trend of consuming iron chelators e.g. roti (high phytates content) and tea (rich in polyphenols but precipitates iron) prevents absorption of dietary iron from intestines. Therefore patients can be counseled to benefit from iron in diet in addition to starting oral iron therapy as; in future the harmful effects of IDA in our next generation may become more pervasive.

INTRODUCTION

Anemia is a medical condition in which the red 
blood cell counts or their physiological oxygen carrying capacity is insufficient to meet the age, sex, altitude and physiological state requirements of the body. This may be caused by a decrease production, an increased loss, nutritional deficiencies, genetic conditions, inflammation or infections. Serum hemoglobin is an indicator for anemia however; it does not establish the cause or type of anemia. According to WHO, a decrease in hemoglobin concentration to $<12$ $\mathrm{gm} / \mathrm{dl}$ in non-pregnant females at sea level, a reduction in total Red Cell Count $<3.8 \times 10 \mathrm{E} 12 / \mathrm{L}$ is considered anemia or a hematocrit of $<36 \%$. $^{1,2}$ According to $\mathrm{WHO}$, an estimated 2 billion people, that is $30 \%$ of the world's population suffers from anemia of various types amongst which Iron Deficiency Anemia (IDA) is most prevalent type, affecting nearly 800 million people globally. ${ }^{3}$ It is characterized by sub optimal serum Iron profile, decrease in iron stores (serum ferritin) to $<12$ ug/l, disturbed hematological parameters and a microcytic hypochromic picture of red blood cells and is a major public health problem worldwide. According to National Nutrition Survey of Pakistan 2011 (NNS) statistics, $50.4 \%$ of non-pregnant women have IDA with a prevalence of $49.3 \%$ in Urban and $50.9 \%$ in rural women. This situation has worsened from the National NNS of 2001 where IDA prevalence was $28.4 \% .{ }^{4}$ Iron deficiency greatly impacts the growth, cognitive performance, health of pregnant women and productivity of all individuals. In women of childbearing age, in addition to decreased levels of energy, it is a risk factor for complications of pregnancy and low birth weight baby. Iron deficiency is a major cause of generalized weakness and fatigue and can remain undiagnosed for a long time before the depletion of iron stores causes IDA and any major functional deficit to patients. ${ }^{5}$ Iron Deficiency Anemia is also an independent cause of increase in morbidity and mortality at all ages. ${ }^{6}$

There is $3 \mathrm{gm}$ of elemental iron in the body two third in the form of hemoglobin and one third in storage forms of ferritin, hemosiderin and myoglobin. ${ }^{7}$ The human body stores and recirculates iron in a closed system to maintain the body's iron requirement. However, an average daily loss of $0.1 \%$ through urine, sweat and feces occurs which needs to be replenished by 1-2 $\mathrm{mg}$ of daily intake of iron in diet. Recommended iron intake is $8 \mathrm{mg}$ for males and $18 \mathrm{mg}$ for menstruating females which can replace only the losses of normal physiological states. ${ }^{8}$ Therefore, without significant blood loss, deficiency of iron is mostly associated with insufficient dietary intake, malabsorption or incorrect intake.9,10 Dietary factors specifically affect 70 million individuals in resource constrained countries and result in depletion of iron stores. ${ }^{11}$

Dietary iron is available in the biochemical forms of heme and non-heme. Heme sources (animal origin) contain iron in ferrous form which is readily absorbed whereas the non-heme sources (grains, vegetables, fruits) contain iron in ferric form which requires reduction before absorption can take place. Non-heme iron absorption is promoted by presence of ascorbic acid and heme iron whereas consumption of phytates in grains, polyphenols/tannins in tea and calcium in dairy inhibit absorption of both ferric and ferrous ions. ${ }^{12}$ Rich sources of dietary iron are organ meats -liver, heart, red meat- beef, mutton, egg yolk, green vegetables- spinach, mustard greens, grains, lentils and fruits like dry dates and figs. All these are indigenous in Pakistan and majority of these are abundantly available in Pakistan at affordable costs $^{13}$ throughout the year. If consumed correctly and regularly in adequate amounts, they can help prevent iron deficiency. This study was hence conducted to determine the patterns of dietary intake of indigenous iron sources among female IDA patients belonging to the urban middle income population of Karachi who have access and affordability to iron rich food. Corresponding hematological parameters were also recorded.

\section{MATERIAL AND METHODS}

This was a cross sectional study conducted at three tertiary care centers of Ziauddin Hospital located at Clifton, Kemari and North Nazimabad. CBC reports of the lab database from previous three months were reviewed and females who had a Hemoglobin, Mean Corpuscular Volume and 
Hematocrit consistent with Iron Deficiency Anemia were identified. The selected population was then contacted by principal investigator, explained about the study and invited to participate. A total of 215 individuals consented to participate. They were asked to meet the investigator at the medicine clinic of their nearest campus on specified time to determine eligibility, give written informed consent and undergo history, clinical exam, 7 day diet recall questionnaire and blood sample collection for baseline iron studies.

\section{Inclusion Criteria}

Females with recent $\mathrm{CBC}$ reports showing low levels of hemoglobin, MCV and hematocrit with hypochromic, microcytic blood film who were not currently taking iron supplements and were otherwise healthy and non-pregnant.

\section{Exclusion Criteria}

Patients with any other known cause of anemia, pregnant, childbirth during last one year, any chronic disease of heart, liver, gastrointestinal tract or kidneys, recent history of malaria/dengue, recent history of injury/surgery/heavy bleeding and patient receiving blood transfusions within one month or taking physician/self-prescribed iron supplements three week prior to this study were excluded.-

A written and informed consent was then taken from eligible individuals by the principal investigator. Participants were clinically assessed for signs of anemia (pallor) and asked about symptoms of fatigue, lethargy/weakness, breathless and pica (a craving to eat substances other than normal food ice, soil). A 7-day food frequency recall questionnaire to assess daily and weekly dietary intake of commonly available iron rich foods was filled by each participant. Four categories of heme source food - organ meat, beef, chicken and fish and ten categories of non-heme source foods - flatbread, white bread, lentils, beans, green leafy vegetables, dates/figs, raisins, tea/coffee, dalia and others were included in the questionnaire. A marked cup was used to demonstrate 1 serving size equal to $3 / 4 \mathrm{cup} / 3 \mathrm{oz}$ 165 grams. The nutritional content of iron per serving was calculated using the reference range from the US department of agriculture's nutrient database website ${ }^{14}$ and used to calculate total iron intake per week (Table 2). This was divided by 7 to obtain average daily intake. Blood sample of $5 \mathrm{ml}$ using aseptic techniques was then drawn for iron profile studies.

Complete blood count (hemoglobin, hematocrit, red cell count, mean corpuscular volume, mean corpuscular hemoglobin, mean corpuscular hemoglobin content and platelets) were done by automated hematology analyzer Beckman coulter and peripheral smear was reviewed for RBC morphology by researcher.

Serum Iron and Total Iron Binding Capacity estimation was done by calorimetric method and Serum Ferritin by immunoturbidimetric method on Roche Hitachi P-800 automated analyzer. TSAT\% was measured by the calculation, serum iron levels / TIBC X 100.

Study was approved by the Ethical Review Committee of Ziauddin University, Karachi and is part of broader research on "Serum hepcidin levels in IDA patients and their response to iron replacement therapy".

\section{RESULTS}

Database was created in SPSS version 20. Descriptive frequencies were obtained. Significance testing and correlation analysis was done for iron intake and hematological parameters.

A total of $n=141$ patients were found eligible of which $75.2 \%(n=106)$ were married. The mean age was $29.41 \mathrm{SD} \pm 14$ years. The prevalence of IDA signs and symptoms is shown in Figure- 1 and $38.2 \%(n=54)$ of our subjects had pica for one or more substance as shown in Figure-2. According to WHO criteria for hemoglobin level in anemia in non-pregnant females at sea level, $16.31 \%$ $(\mathrm{n}=23)$ had severe IDA ( $\mathrm{Hb}<8.0 \mathrm{~g} / \mathrm{dl}), 52.48 \%$ $(\mathrm{n}=74)$ had moderate IDA (Hb $8.0-10.9 \mathrm{~g} / \mathrm{dl})$, $18.44 \%(\mathrm{n}=26)$ had mild IDA (Hb $11.0-11.9$ $\mathrm{g} / \mathrm{dl})$ and $12.76 \%(\mathrm{n}=18)$ subjects had normal 
$(\mathrm{Hb} 12 \mathrm{~g} / \mathrm{dl}$ or $>$ ). Those with normal hemoglobin however had $<36 \%$ hematocrit and $<12 \mathrm{ug} / \mathrm{l}$ of serum ferritin indicating their marginal status for IDA development.

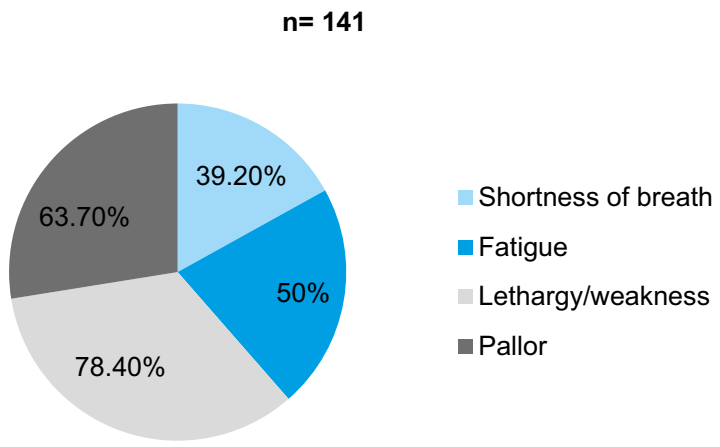

Figure-1. Prevalence of signs and symptoms of IDA in study sample

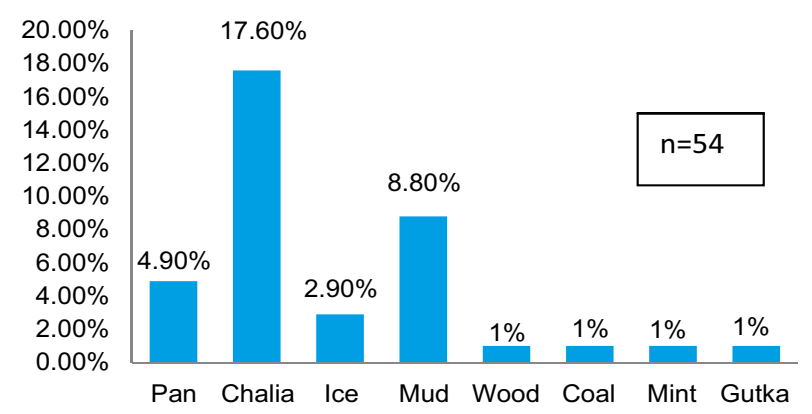

Figure-2. Prevalence of different types of pica in the study population
Among the study sample, mean iron intake/day was $6.41 \pm 4.39 \mathrm{mg} /$ day. Median heme and non heme iron intake / week were $8.0 \mathrm{mg}$ and $28.0 \mathrm{mg}$ respectively. Majority of the population was consuming non-heme sources of iron. Organ meat and dates, two very common and affordable iron rich foods were not consumed by $40 \%$ of study population however consumption of dates increased by $20 \%$ during the holy month of Ramazan. The iron intake and hematological profiles are given in Table-I.

Using a one sample t-test, there was strong correlation between daily iron intake and hemoglobin concentration with a 2-tailed significance of $p=0.000$. Pearson linear correlation was $r=1$ or $>0.5$ between all hematological and iron parameters with a 2-tailed significance between $p<0.01$ to $<0.05$.

\section{DISCUSSION}

The daily iron intake in our study population is way below the recommended allowance for nonpregnant females. Literature shows that the actual bioavailability of iron from a mixed diet is between 14 to $18 \% .{ }^{15}$ Thus from a diet already low in iron content in our study sample, actual iron made available to the body is further reduced to a negative balance.

\begin{tabular}{|l|c|c|c|c|}
\hline \multicolumn{1}{|c|}{ Parameters (units) } & Mean & $\mathbf{\pm S D}$ & SE & Median IQR 25-75 \\
\hline Iron from heme source/week in mg & 12.09 & 14.460 & 1.2 & 8.00 \\
\hline Iron from non-heme in mg source/week & 33.38 & 25.406 & 2.2 & 28.00 \\
\hline Total iron /week in mg & 44.8 & 30.806 & 2.7 & 39.00 \\
\hline Average Daily iron in mg & 6.41 & 4.391 & 0.38 & 5.57 \\
\hline & & & & \\
\hline Hb (gm/dl) & 09.41 & 1.559 & 0.149 & 09.60 \\
\hline Hct (\%) & 30.15 & 4.208 & 0.404 & 30.00 \\
\hline RBC (x10E12/L) & 04.25 & 0.564 & 0.540 & 04.27 \\
\hline MCV (fl) & 70.80 & 8.890 & 0.855 & 70.50 \\
\hline MCH (Pg) & 22.309 & 3.532 & 0.339 & 22.00 \\
\hline MCHC (gm/dl) & 30.78 & 2.094 & 0.201 & 31.00 \\
\hline Ferritin (ng/ml) & 16.29 & 19.285 & 1.855 & 10.25 \\
\hline Serum Iron (ug/dl) & 28.12 & 15.154 & 1.479 & 25.00 \\
\hline TIBC (ug/dl) & 361.56 & 131.962 & 12.757 & 410.00 \\
\hline TSAT (\%) & 9.33 & 6.179 & 0.603 & 07.75 \\
\hline \multicolumn{1}{|c|}{ Table-l. Estimated iron intake in mg from 7 day dietary recall and corresponding Blood parameters } \\
\hline
\end{tabular}




\begin{tabular}{|c|c|c|}
\hline $\begin{array}{c}\text { Heme Food (Animal Source) } \\
\begin{array}{c}1 \text { serving }=3 / 4 \text { cup }=30 z=63 \\
\text { gms }\end{array}\end{array}$ & $\begin{array}{l}\text { Daily iron } \\
\text { intake(mg) }\end{array}$ & \% DV* \\
\hline $\begin{array}{l}\text { High iron content } \\
\text { Chicken liver }\end{array}$ & 11 & 29 \\
\hline Beef liver & 5.2 & 61 \\
\hline $\begin{array}{l}\text { Medium iron content } \\
\text { Beef boti /Roast Pasanday, } \\
\text { Shammi Kabab, }\end{array}$ & 3.1 & 17 \\
\hline Beef Qeeema(85\%lean) & 2.2 & 12 \\
\hline $\begin{array}{l}\text { Low iron content } \\
\text { Chicken }\end{array}$ & 0.9 & 05 \\
\hline Fish & 0.8 & 04 \\
\hline $\begin{array}{c}\text { Non heme Food (Plant } \\
\text { Source) }\end{array}$ & $\begin{array}{l}\text { Daily iron } \\
\text { intake(mg) }\end{array}$ & $\%$ DV \\
\hline $\begin{array}{l}\text { Dalia (instant fortified, cooked } \\
\text { in water, } 1 \text { pack) }\end{array}$ & 11 & 61 \\
\hline Roti/ Chappati/ Paratha (1) & 0.7 & 04 \\
\hline Lentils/ Daal (3/4 cup cooked) & 6.6 & 37 \\
\hline $\begin{array}{l}\text { Soya Bean/ Kidney Beans/ } \\
\text { White Lobia ( } 1 \text { cup) }\end{array}$ & 5.2 & 29 \\
\hline Spinach/ Palak fresh (1/2 cup) & 3.2 & 18 \\
\hline $\begin{array}{l}\text { Raisins/ Kishmish (seedless } \\
1 / 2 \text { cup) }\end{array}$ & 1.6 & 9 \\
\hline Bread White 1 Slice/ Rusk & 0.9 & 5 \\
\hline Dates (100gm) & 0.9 & 5 \\
\hline Figs (Anjeer, 100gms) & 0.37 & 1 \\
\hline \multicolumn{3}{|c|}{$\begin{array}{l}\text { Table-II. Food table showing the iron class, Source } \\
\text { and iron content of different food. } \\
\text { *\%DVs=Daily value are reference numbers developed by the Food and } \\
\text { Drug Administration (FDA) to help consumers determine if a food contains } \\
\text { a lot or a little of a specific nutrient. A food providing } 5 \% \text { of the DV or } \\
\text { less is a low source while a food providing } 10-19 \% \text { of the DV is a good } \\
\text { source. A food that provides } 20 \% \text { or more of the DV is high in that nutrient. } \\
\text { Reference: Office of Dietary Supplements.national institute of health } \\
\text { http://ods.od.nih.gov/About/Accessibility_Statement.aspx }\end{array}$} \\
\hline
\end{tabular}

The results of this study show that signs and symptoms of IDA were present in our study population however they were not taking any iron supplements to correct their deficiency. This identifies the lack of awareness of nutritional deficiencies and their signs and symptoms even among reproductive age females who are at risk of IDA due to their menstrual cycles. The most frequent pica was betel nut (chalia). Betel nut has high iron content and the high prevalence of betel nut chewing in Pakistan may hence be linked to presence of sub clinical iron deficiency. ${ }^{16,13}$ The corresponding hematological profiles were also significant for low iron levels in body which is evidence of a chronic insufficient intake of iron. The NNS 2011 also found $26.8 \%$ of Pakistani population had low ferritin level which is indicator of depleted iron stores. An assessment of diet from previous week revealed that most of our population was consuming non-heme sources and only small percentage was consuming heme iron sources despite their availability, accessibility and affordability. Among the iron rich heme sources is liver, which is easily available at low cost but we found that it is not frequently consumed by the IDA population. These findings are similar to a study on iron content of mixed Pakistani diet that found that an average $31 \pm 9.5 \mathrm{mg} / \mathrm{d}$ with a range between 12 to $52 \mathrm{mg} / \mathrm{d}$ is present in daily diet which is sufficient to meet the daily allowance. However, the bioavailability remained low possibly due to the composition which was found to be $71 \%$ plant source food, $17 \%$ dairy and only $5 \%$ animal source food as well as the presence of iron inhibitors, such as phytates in whole grain flat bread, and tea (consumed with or just after meals) containing polyphenols in our food consumption habits. ${ }^{17}$ We did not study this consumption pattern however it is the popular pattern and highlights the need for awareness on this dietary issue as these factors contribute to IDA even when an iron rich diet is consumed. The NNS 2011 also showed that knowledge of iron, iron rich foods and impact of deficiency on health among Pakistani population is only $42 \%$ with $17 \%$ in rural and $24.8 \%$ in urban population. Only $20.1 \%$ knew about red meat as good source and $36.5 \%$ knew about leafy green as good source of iron. Therefore this lack of iron food sources can be attributed to lack of knowledge in our study population about indigenous iron rich foods and the correct consumption practice.

Due to the unfortunate gastrointestinal discomfort experienced most people with oral iron supplements and subsequent discontinuation and non-compliance to therapeutic or maintenance regimens, it is all the more imperative that focus is put on increasing the indigenous dietary sources 
of iron to prevent depletion of iron stores. ${ }^{18,19}$ Dietary interventions will have advantages over supplementation in relation to compliance, acceptability and cost effectiveness. Additionally, literature has shown that though Iron supplements cause higher increase in serum ferritin level and diet causes a comparative lower increase, the dietary intervention continues to increase the ferritin stores over long term as compared to supplements due to associated compliance issues. ${ }^{20}$ Additionally, improving dietary habits of reproductive age women for iron content will benefit the whole family as in the Pakistani culture, they are responsible for food preparation. The Iron fortification of common food sources could improve the intake however presence of iron inhibitors in our dietary consumption patterns will possibly negate the effect. Moreover, the added cost of packaged, iron fortified foods keeps it out of reach of the most vulnerable low socio economic population. Thus health awareness and behavioral change communication is an important intervention in our population due to available, affordable and accessible indigenous iron food sources.

Our study population was females of reproductive age. This study demonstrates the importance of routine checkups and health education targeting this age group to screen, diagnose and treat iron deficiency at an earlier stage as these women have to bear the burden of childbirth and will contribute to anemia in the baby as well as more complications during pregnancies.

\section{CONCLUSION}

Lack of iron from indigenous dietary sources contributes significantly to IDA prevalence in the female urban population of Karachi. IDA patients are also suffering from symptoms, have hematological evidence of deficiency but not correcting it through diet improvement or supplements. This study hence concludes that there is need to increase awareness about IDA and its symptoms among general population and educate them about easily available dietary sources, their correct preparation for maximum utilization and recommended amounts to prevent the hidden consequences and silent suffering due to IDA.

Copyright (C) 25 Aug, 2016.

\section{REFERENCES}

1. WHO Hemoglobin concentration for the diagnosis of anemia and severity. Vitamin and Mineral Nutrition Information System. Geneva, World Health Organization 2011. (WHO/NMH/NHD/MNM/11.1) http:// www.who.int/vmnis/indicators/haemoglobin.pdf

2. Beutler $E$, Waalen J. The definition of anemia: what is the lower limit of normal of the blood hemoglobin concentration? Blood. 2006;107(5):1747-50.

3. McLean E, Cogswell M, Egli I, Wojdyla D, De Benoist B. Worldwide prevalence of anaemia, WHO vitamin and mineral nutrition information system, 1993-2005. Public health nutrition. 2009;12(04):444-54.

4. National Nutrition Survey 2011, Planning Commission, Planning and Development Division, Government of Pakistan

5. Brittenham GM. Pathophysiology of iron homeostasis. Hematology: basic pricipals and practice pages 427 436. $6^{\text {th }}$ Ed 2013. S Saunders, Philadelphia.

6. Nissenson AR, Goodnough LT, Dubois RW. Anemia: or just an innocent bystander? Arch Intern Med 2003;163:1400-1404.

7. Alleyne M, Home MK, Miller JL. Individualized treatment for iron deficiency anemia in adults. Am J Med 2008;12(11):943 -948.

8. Fei C. Iron deficiency anemia: a guide to oral iron supplements. Clinical Correlation 2015.

9. Schrier SL. Causes and diagnosis of anemia due to iron deficiency. Available from: www UpToDate com Last updated November. 2003;6.

10. Zlotkin S. Clinical nutrition: 8. The role of nutrition in the prevention of iron deficiency anemia in infants, children and adolescents. Canadian Medical Association Journal. 2003;168(1):59-63

11. Zimmermann, Michael $B$ et al. Nutritional iron deficiency. The Lancet $2007 ; 370$ (9586):511-520

12. Hallberg $L$. Wheat fiber, phytates and iron absorption. Scand J Gastroenterol Suppl. 1987;129:73-9.

13. Food Consumption Table for Pakistan 2001. Published by Ministry of Planning and Development, Islamabad, UNICEF and Department of Agriculture, NWFP. 
14. Schakel S, Sievert Y, Buzzard I. Sources of data for developing and maintaining a nutrient database. Journal of the American Dietetic Association. 1988;88(10):1268-71.

15. Hurrell R, Egli I. Iron bioavailability and dietary reference values. Am J Clin Nut 2010;91:1461S-75.

16. Akhter P, Mohammad D, Orfi SD, Ahmed N, Rehman $\mathrm{K}$. Assessment of daily iron intake for the Pakistani population. Nutrition \& Food Science. 2005;35(2):109117.DOIhttp://dx.doi.org/10.1108/00346650510585895.

17. Galloway R, McGuire J. Determinants of compliance with iron supplementation: supplies, side effects or physiology? Soc Sci Med 1994;39:381-90

18. Hallberg L, Ryttinger L. Solvell L. Side effects of oral iron therapy. A double-blind study of different iron compounds in tablet form. Acta Med Scand 1966;459(suppl);3-10

19. Patterson AJ, Brown WJ, Roberts DCK, Seldon MR. Dietary treatment of iron deficiency in women of childbearing age. Am J Clin Nut 2001; 74:650-6.

20. National Institute of Health, office of Dietary Supplements, Health Information Iron Fact Sheet.. Updated Feb 1, 2016. .USA.gov

\section{PREVIOUS RELATED STUDY}

Ghazala Irshad, Saghir Ahmad Jafri, Samina Kousar, Irshad Ali. IRON DEFICIENCY ANEMIA; SIGNIFICANCE OF SERUM FERRITIN IN DIAGNOSIS IN PREGNANT FEMALES OF PAKISTAN (Original) Prof Med Jour 18(3) 470-474 Jul, Aug, Sep 2011.

Raheela Farhat, Mahnaaz Roohi. IRON DEFICIENCY ANEMIA; SAFETY AND EFFICACY ON INTRA VENOUS IRON SUCROSE VERSUS ORAL FERROUS SULPHATE (Original) Prof Med Jour 14(2) 263-265 Apr, May, Jun, 2007.

Shaheen Ahmed, Naeem Fareed, Nadeem Sadiq, Salman Ali, Mehboob Sultan, Umar Khurshid. IRON DEFICIENCY ANEMIA; SINGLE VERSES THREE TIMES DAILY DOSES OF FERROUS SULPHATE (Original) Prof Med Jour 16(2) 209-215 Apr, May, Jun, 2009.

Shezadi Sabah, Musarat Ramzan, Irum Fatima. IRON DEFICIENCY ANEMIA; ROLE OF NUTRITIONAL DEPRIVATION AMONG FEMALE PATIENTS OF REPRODUCTIVE AGE GROUP (Original) Prof Med Jour 17(4) 686-690 Oct, Nov, Dec 2010.

\section{AUTHORSHIP AND CONTRIBUTION DECLARATION}

\begin{tabular}{|c|c|c|c|}
\hline Sr. \# & Author-s Full Name & Contribution to the paper & Author $=\mathbf{s}$ Signature \\
\hline 1 & Dr. Ghazala Masood Farrukh & $\begin{array}{l}\text { Designed and conducted } \\
\text { research, interviewed } \\
\text { patient, acquired and } \\
\text { interpreted data, co wrote } \\
\text { and critically reviewed } \\
\text { manuscript for intellectual } \\
\text { content }\end{array}$ & \\
\hline 2 & Dr. Zainab Hasan & $\begin{array}{l}\text { Manuscript writing, Data } \\
\text { analysis, interpretation } \\
\text { and results }\end{array}$ & $\longrightarrow$ \\
\hline 3 & Samar Ikram & $\begin{array}{l}\text { Data entry, literature } \\
\text { review, contributed to } \\
\text { results }\end{array}$ & \\
\hline 4 & Batha Tariq & $\begin{array}{l}\text { Data entry, literature } \\
\text { review, contributed to } \\
\text { results }\end{array}$ & \\
\hline
\end{tabular}

